\title{
Taking up the gauntlet: Pharmacist delivery of primary care services
}

\section{Alexandra Fletcher \\ (McGill University) \\ News Reporter (HSI 2013-2014)}

With Canada's aging population and the concomitant burden of chronic disease, physicians need more help than ever in coping with patients with multi-morbidities who require complex drug regimens. Community pharmacists are increasingly being called upon to move beyond their traditional role as drug purveyors and expand the scope of their clinical duties. For instance, pharmacists from across Canada have been engaging in expanded activities, such as providing emergency prescription refills, renewing and extending prescriptions, changing drug dosage and formulation, making therapeutic substitutions, prescribing for minor ailments, initiating prescription drug therapy, ordering and interpreting lab tests and administering drugs by injections (see table 1). The logic behind introducing these new responsibilities is that during their schooling, pharmacists have been trained in many domains of disease management, which they do not end up actually applying once they start practicing. In order to use pharmacists' specialized

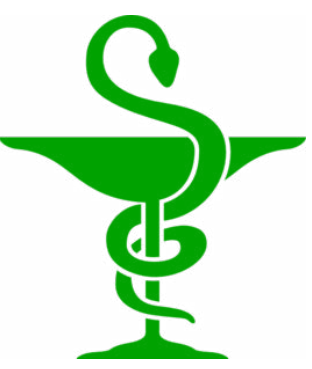
knowledge more effectively, regulated technicians are hired by pharmacies to take over the routine, product-focused aspects of drug dispensing, such as ensuring that the right drug and label have been added to the prescription.

\section{Table 1: Summary of Pharmacists' expanded scope of practice across Canada}

\begin{tabular}{|c|c|c|c|c|c|c|c|c|c|c|c|c|c|c|}
\hline & & BC & $A B$ & SK & MB & ON & QC & NB & NS & PEI & NL & NWT & YU & NT \\
\hline \multicolumn{2}{|c|}{ Provide emergency prescription refills } & Y & $\mathrm{Y}$ & $\mathrm{Y}$ & $\mathrm{Y}$ & $\mathrm{Y}$ & $\mathrm{P}^{6,7}$ & Y & Y & $\mathrm{N}$ & $\mathrm{Y}$ & $\mathrm{Y}$ & $\mathrm{N}$ & $\mathrm{N}$ \\
\hline \multicolumn{2}{|c|}{ Renew and extend prescriptions } & Y & Y & Y & $\mathrm{Y}^{3}$ & $\mathrm{Y}$ & $\mathrm{P}^{6}$ & $\mathrm{Y}$ & $\mathrm{Y}$ & $\mathrm{Y}$ & $\mathrm{Y}$ & $\mathrm{Y}$ & $\mathrm{N}$ & $\mathrm{N}$ \\
\hline \multicolumn{2}{|c|}{ Change drug dosage/formulation } & $Y$ & $Y$ & Y & Y & $\mathrm{Y}$ & $P^{6,7}$ & Y & Y & $\mathrm{Y}$ & Y & $\mathrm{N}$ & $\mathrm{N}$ & $\mathrm{N}$ \\
\hline \multicolumn{2}{|c|}{ Make therapeutic substitutions } & $\mathrm{Y}$ & $\mathrm{Y}$ & Y & $\mathrm{N}$ & $\mathrm{N}$ & $P^{6,7}$ & $\mathrm{Y}$ & Y & Y & $Y^{10}$ & $\mathrm{~N}$ & $\mathrm{~N}$ & $\mathrm{~N}$ \\
\hline \multicolumn{2}{|c|}{ Prescribe for minor ailments } & $\mathrm{N}$ & $\mathrm{Y}^{1}$ & Y & Y & $\mathrm{N}$ & $P^{6,7}$ & $P$ & $\mathrm{Y}$ & $\mathrm{N}$ & $\mathrm{N}$ & $\mathrm{N}$ & $\mathrm{N}$ & $\mathrm{N}$ \\
\hline \multicolumn{2}{|c|}{ Initiate prescription drug therapy } & $\mathrm{N}$ & Y & $\mathrm{Y}^{2}$ & Y & $Y^{4}$ & $P^{6,7}$ & $Y^{9}$ & $\mathrm{Y}^{2}$ & $\mathrm{~N}$ & $\mathrm{~N}$ & $\mathrm{~N}$ & $\mathrm{~N}$ & $\mathrm{~N}$ \\
\hline \multicolumn{2}{|c|}{ Order and interpret lab tests } & $\mathrm{N}$ & Y & $\mathrm{N}$ & $\mathrm{Y}$ & $P$ & $\mathrm{P}^{6}$ & $\mathrm{Y}$ & Y & $\mathrm{N}$ & $\mathrm{N}$ & $\mathrm{N}$ & $\mathrm{N}$ & $\mathrm{N}$ \\
\hline \multicolumn{2}{|c|}{ Administer drugs by injection } & Y & Y & $\mathrm{N}$ & $\mathrm{Y}$ & $Y^{5}$ & $\mathrm{P}^{6,8}$ & Y & Y & $\mathrm{P}$ & $P$ & $\mathrm{~N}$ & $\mathrm{~N}$ & $\mathrm{~N}$ \\
\hline \multicolumn{15}{|c|}{$\begin{array}{l}\text { Table adapted from Blueprint for Pharmacy: http://blueprintforpharmacy.ca/docs/resource-items/pharmacists'-expanded-scope-of-practice_summary-chart---cpha---january-2014-from-graphicsD } \\
\text { F4DC970F6835A01BE1C1989.pdf }\end{array}$} \\
\hline \multicolumn{15}{|c|}{ 1. AB: pharmacists in Alberta who have "additional prescribing authority" can prescribe a Schedule I drug (prescription-only) for the treatment of minor ailments } \\
\hline \multicolumn{15}{|c|}{ SK \& NS: only as part of assessment and prescribing for minor ailments } \\
\hline \multicolumn{15}{|c|}{ MB: as Continued Care Prescriptions under section 122 of the Regulations to the Pharmaceutical Act } \\
\hline \multicolumn{15}{|c|}{ ON: restricted to prescribing specified drug products for the purpose of smoking cessation } \\
\hline \multicolumn{15}{|c|}{ ON: administration of influenza vaccination to patients five years of age and older; administration of all other injections and inhalations for demonstration and educational purposes } \\
\hline \multicolumn{15}{|c|}{$\begin{array}{l}\text { QC: pending Orders in Council (activity enable } \\
\text { by Orders in Council on August 22, 2013) }\end{array}$} \\
\hline \multicolumn{15}{|c|}{ QC: when authorized by a physician by means of a "collective prescription" (i.e., collaborative practice agreement) } \\
\hline \multicolumn{15}{|c|}{ 8. QC: for demonstration purposes only } \\
\hline \multicolumn{15}{|c|}{ NB: prescribing constitutes adapting, emergency prescribing or within a collaborative } \\
\hline & NL: limited to non-formulary generic substit & & & & & & & & & & & & & \\
\hline
\end{tabular}


This frees up a pharmacist's time for more complex tasks, such as the activities described above.

These changes have not been adopted haphazardly; they are predicated on a significant body of evidence showing that pharmacists can improve health outcomes of patients. For instance, a 2010 systematic review and meta-analysis by Chisholm-Burns et al looked at the impact of pharmacy interventions on various health outcomes, which yielded distinctly positive assessments. ${ }^{1}$ At the meta-analysis level, pharmacy interventions led to lower hemoglobin A1c and LDL levels, as well as decreased blood pressure. ${ }^{1}$ Although there were not enough randomized control trials (RCT) to perform a meta-analysis on hospitalizations and readmission data, the evidence indicated that pharmacists' interventions reduced these indicators in $51.4 \%$ of cases, with no effect in the other cases. ${ }^{1}$ The same authors were also able to show significant improvements in both safety (reduction in adverse drug events) and humanistic (medication adherence, patient satisfaction, quality of life and general health) outcomes at the meta-analysis level. ${ }^{1}$ Results like these led Janet Cooper, Senior Director of Professional and Membership Affairs at the Canadian Pharmacy Association (CPhA), a licensed pharmacist herself, to be convinced of the positive role that pharmacists can have in improving health care delivery.

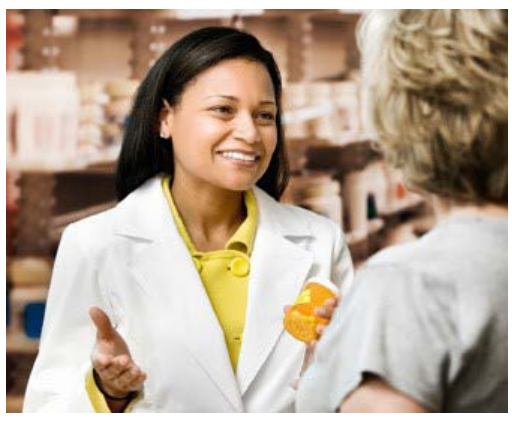

The process of change is being guided and monitored by Blueprint for Pharmacy, an ongoing practice change initiative spearheaded by the CPhA and managed by Ms. Cooper (http://www. blueprintforpharmacy. ca). The Blueprint was conceptualized in 2006 upon recognizing that pharmacy practice in Canada was rapidly evolving. The $\mathrm{CPhA}$ considered that the best approach would be to provide a regulated framework in which pharmacies and jurisdictions could pursue change. The CPhA also explicitly decided to de-centralize ownership of the project by bringing in key players from both the national and provincial levels, as well as some major pharmacy chains. ${ }^{2}$ This initiative is helping to standardize the scope of pharmacy practice across the country, as is the case with the medical profession. However, not all pharmacists are supportive of expanding their scope of practice. This is why, as Ms. Cooper highlighted, "provincial legislation is enabling, but pharmacists are not being forced to do it." Of course, pharmacists are not the only ones with hesitations; physicians, as well as other health care professionals, do have legitimate concerns regarding the fragmentation of care if they were to send their patients to the pharmacy for various procedures. As Ms. Cooper explained, solutions to this issue have been developed in Alberta, where a province-wide prescription drug network contains all patient prescription data history, and pharmacists have access to lab values. As well, appropriate payment schemes exist to encourage communication between pharmacists and physicians. In contrast, in provinces with fewer resources for integrative care, pharmacists must still rely on verbal and fax communication with the patient's physician. According to Ms. Cooper, physicians have a tendency to worry that pharmacists might take away their patients, along with the additional revenue. This point was also made by Dr. Grabenstein, who is the Senior Medical Director for Adult Vaccines for Merck Vaccines, and the individual responsible for producing the "PharmacyBased Immunization Delivery," a CDC (Centers for Disease Control and Prevention)-recognized 20-hour immunizationtraining course coordinated by the American Pharmacists Association (APhA). With respect to lost revenue, his work showed that pharmacist immunizers increase absolute vaccination rates; people vaccinated by pharmacists are often those that would not have been vaccinated, not individuals who have left their physician to be vaccinated by pharmacists. ${ }^{3}$ To explain this, he conducted a survey that found that "people vaccinated at pharmacies valued access and convenience, whereas people who visited their physician valued existing personal relationships." ${ }^{4}$ Although Dr. Grabenstein did not explore these considerations in relation to other services provided by pharmacists, patients may make choices to either visit their pharmacist or physician based on similar values. He conjectured that the accessibility of pharmacists takes on many dimensions, such as geographic proximity, extended hours of operation, and ease with which individuals can talk with their pharmacist. These reasons can help explain why individuals might visit their pharmacist, rather than their doctor. $>$ 
Moreover, Canadians are very supportive of the direction pharmacy is taking. An Ipsos Reid poll from June 2012 found that over $70 \%$ of Canadians either strongly support or somewhat support pharmacists engaging in activities as broad as physiotherapy clinics, providing $\mathrm{X}$-rays and inhome medical care, among others. ${ }^{5}$ Revealingly, a majority of Canadians (82\%) believe that if these products and services are owned and offered by pharmacies, the quality of treatment or service would be higher $(28 \%)$ or the same $(54 \%)$ as treatment currently available. ${ }^{5}$ Whether these responses reflect a general desire for a more responsive and accessible health care system or a true belief in the capacity of pharmacists to provide these services is difficult to discern; most likely, both influences are at play. What is important is that pharmacists are rising to the challenge. With over 33,000 licensed pharmacists across Canada, we can expect that mobilizing this highly-trained workforce can have important consequences on the health of Canadians.

\section{References}

1. Browne AJ, Smye VL, Rodney P, Tang SY, Mussell B, O'Neil J. Access to Primary Care From the Perspective of Aboriginal Patients at an Urban Emergency Department. Qual Health Res. 2011;21(3):333-348.

2. Browne AJ, Varcoe CM, Wong ST, Smye VL, Lavoie J, Littlejohn D, Tu D, Godwin O, Krause M, Khan KB, Fridkin A, Rodney P, O'Neil J, Lennox S. Closing the health equity gap: evidence-based strategies for primary health care organizations. International Journal for Equity in Health. 2012;11:59.

3. Peiris $D$, Brown A, Cass A. Addressing inequities in access to quality health care for indigenous people. Can Med Assoc J. 2008;179(10):985-986.

4. Towle A, Godolphin W, Alexander T. Doctor-patient communications in the aboriginal community: Towards the development of educational programs. Patient Educ Couns. 2006;62(3):340-346.

5. Wilson K, Cardwell N. Urban Aboriginal health. Examining inequalities between Aboriginal and non-Aboriginal populations in Canada. Canadian Geographer-Geographe Canadien. 2012;56(1):98-116.

6. Gao S, Manns BJ, Culleton BF, Tonelli M, Quan H, Crowshoe L, Ghali WA, Svenson LW, Ahmed S, Hemmelgarn BR, Alberta Kidney Dis Network. Access to health care among status Aboriginal people with chronic kidney disease. Can Med Assoc J. 2008;179(10):1007-1012.

7. Shan BR, Gunraj N, Hux JE. Markers of access to and quality of primary care for aboriginal people in Ontario, Canada. Am J Public Health. 2003;93(5):798-802.

8. Anderson-DeCouteau, Marcia. White Coat Black Art with Dr. Brian Goldman: Improving the Healthcare System with Dr. Marcia Anderson-DeCoteau (Extended Interview). CBC, October 7, 2013.

9. Campbell DJT, Ronksley PE, Hemmelgarn BR, Zhang J, Barnabe C, Tonelli M, Manns B. Association of enrolment in primary care networks with diabetes care and outcomes among First Nations and low-income Albertans. Open medicine : a peer-reviewed, independent, open-access journal. 2012;6(4):e155-65.

10. Morrison L, Buckeridge DL, Xiao Y, Moghadas SM. The impact of geographical location of residence on disease outcomes among Canadian First Nations populations during the 2009 influenza A(H1N1) pandemic. Health \& Place. 2014;26:53-59.

11. Bhattacharyya OK, Estey EA, Rasooly IR, Harris S, Zwarenstein M, Barnsley J. Providers' perceptions of barriers to the management of type 2 diabetes in remote Aboriginal settings. Int J Circumpolar Health. 2011;70(5):552-563.

12. Buxton JA, Ouellette V, Brazier A, Whiteside C, Mathias R, Dawar M, Mulkins $A$. Bridging the gap in population health for rural and Aboriginal communities: a needs assessment of public health training for rural primary care physicians. Canadian journal of rural medicine : the official journal of the Society of Rural Physicians of Canada = Journal canadien de la medecine rurale : le journal officiel de la Societe de medecine rurale du Canada. 2007;12(2):81-8.

13. Kelly L, Brown JB. Listening to Native patients - Changes in physicians' understanding and behaviour. Canadian Family Physician. 2002;48:1645-1652.

14. Van Herk KA, Smith D, Gold ST. Safe care spaces and places: Exploring urban Aboriginal families' access to preventive care. Health Place. 2012;18(3):649-656.

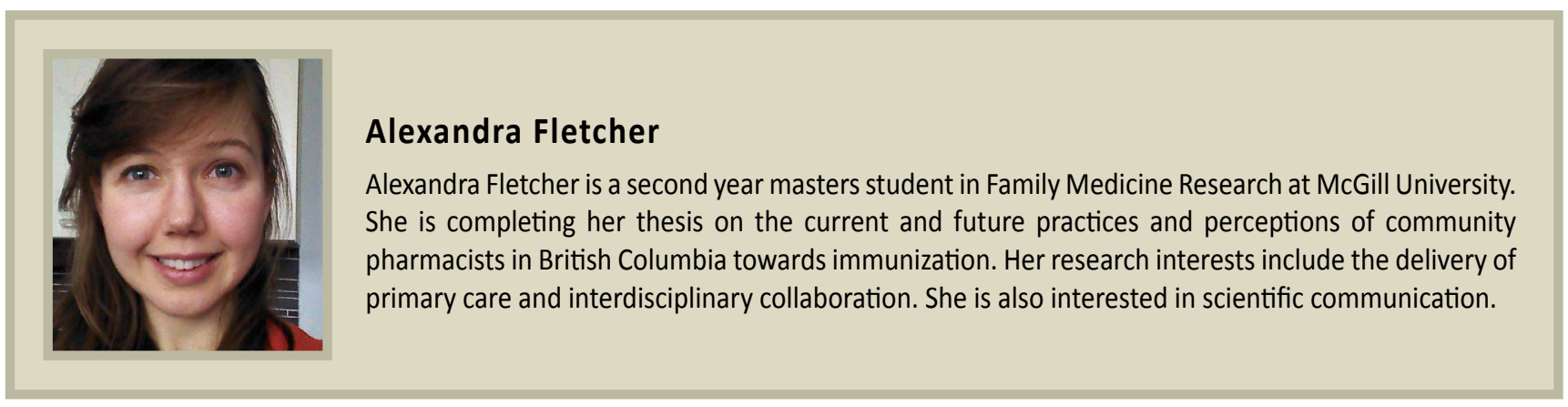

